ESJ Social Sciences

\title{
The Dimension of Textile use in the Expression of Verbal Creativity
}

\author{
Ilona Valantinaite \\ Zivile Sedereviciute-Paciauskiene \\ Vilnius Gediminas Technical University, Vilnius, Lituhiania
}

Doi:10.19044/esj.2022.v18n6p1

Submitted: 14 March 2021

Accepted: 17 February 2022

Published: 28 February 2022
Copyright 2022 Author(s)

Under Creative Commons BY-NC-ND

4.0 OPEN ACCESS

Cite As:

Valantinaite I. \& Sedereviciute-Paciauskiene Z. (2022). The Dimension of Textile use in the Expression of Verbal Creativity. The Apulian Case History. European Scientific Journal, ESJ, 18 (6), 1. https://doi.org/10.19044/esj.2022.v18n6p1

\section{Abstract}

The article investigates the Baltic pre-service Technology teachers' expression of verbal creativity in their final years of study and analyzes the constituent dimension of sustainable textile consumption. The students' verbal creativity was examined using a verbal expression questionnaire compiled following the methodological recommendations of E. P. Torrance for diagnosing a person's creativity. The development of sustainable textile consumption is part of the Technological education curriculum analyzing responsible consumption issues that are becoming more complex. In most cases, education directly depends on the educator's knowledge, skills, values, habits, experience, and communication. The present research disclosed students - pre service teachers understanding that handicrafts are not related to ethnicity, values, or a phenomenon, which calls for exceptional protection. The integral model of tasks on identification/development of verbal creativity expression and identification/development of sustainable textile consumption was presented in the article.

Keywords: Verbal creativity, communication, technology education, sustainable textile consumption

\section{Introduction}

In the last decade, creativity has become the most coveted competence of employees in the job market and in educational practice - one of the main 
competencies to be developed. Creativity is needed both to create technological innovations and to perform small everyday tasks. Due to the great variety of creativity and the amplitude of its application, its measurement becomes difficult. Over the last decades, the fast-growing number of creativity research has been accompanied by the demand for appropriate approaches to measuring creativity (Kim, Cramond, \& Bandalos, 2006, Villanova, Pina E Cunha, 2020). Scholars' growing interest in developing creativity measurement tools allows us to select and adapt methodologies to a specific context. This article's focus is the verbal creativity of the Baltic pre-service Technology teachers in their final years of study. The article analyzes the constituent dimension of sustainable textile consumption. The curriculum and a creative teacher and their competencies play the central role in ensuring sustainable education (Čirčin, 2016; Wilhelm et al., 2019).

The study subject of technologies aims to transmit not only a knowledge of how textiles can be used but also traditional techniques of textile handicraft production. The most crucial factor in ensuring textile handicrafts' survival embraces the teacher's value system, attitudes, and thinking models. Therefore, it was essential to investigate how students - pre-service teachers use their divergent thinking to present possibilities and limitations of textile use and historical origins of textile.

The phenomenon of creativity is one of the essential characteristics of a contemporary, actively functioning individual (Yerevan Communique, 2015) and receives considerable attention from scholars. Creativity in this regard began to gain the attention of pedagogues from about the middle of the previous century (Guilford, 1950). Since that time, creativity and its expression have become deeply significant for most individuals. Its ongoing research seeks to identify the expression of creativity and increase the efficiency of education (Zmigrod, 2014; Beaty et al., 2017; Puryear et al., 2017).

\section{Creativity and divergent thinking}

Creativity as a concept and its relevance to individuals' creative capacity (Puryear et al., 2017) has been the subject of considerable research (Guilford, 1950). Human creativity is related to divergent (imaginative) thinking (Sun et al., 2019), yet it is considered to be one of the most elusive of human abilities (Zmigrod, 2014). Divergent thinking is the propensity for the mind to generate ideas and find solutions to problems outside commonly prescribed expectations (Leclerc, 2017). Divergent thinking is assumed to generate a broad range of solutions initially. In contrast, convergent thinking discerns which solutions are the most appropriate to arrive at the best possible solution (Furley and Memmert, 2015). 
P. B. Paulus and V. R Brown indicate that divergent thinking relies on cognitive processes such as "the retrieval of existing knowledge from memory, and the combination of various aspects of existing knowledge into novel ideas" (Paulus and Brown, 2007, p. 252). Our working memory plays a vital role in utilizing the stockpiled knowledge that helps to form creativity. Creativity allows a person to combine many facts, conclusions, and experiences stored in memory. Also, memory plays an essential role in learning. Well-known Bloom's taxonomy is based on understanding, analyzing, evaluating, memorizing, application, and creation (Bloom, 1956, Krathwohl, 2002). Interestingly, the dimensions of evaluation and creation were added to the renewed taxonomy because scholars believed that creative thinking is a more complex cognitive process than critical thinking. In other words, one can be critical without necessarily being creative, but creative production often requires critical thinking (Krathwohl, 2002).

The Torrance Test of Creative Thinking (TTCT) (Torrance, 1966) is widely used to measure divergent thinking in creativity research. Despite the critique on the validity of the TTCT (Said-Metwaly et. al., 2018), the TTCT has been employed in more than 2,000 published studies (Torrance, 2000).

\section{Sustainability of traditional textile consumption in the school curriculum}

The extent to which a person is ready to act qualitatively and responsibly and how much the nation's intellectual capital will grow depends directly on one's education. The main goal of the educational system in every country is to develop and educate a responsible, creative and intellectual personality and to prepare him/her for life (personal life and labor market) within his/her powers (Yerevan Communique, 2015; Towards a sustainable Europe by 2030, 2017). Teachers certainly have the most significant role in fostering students' creative thinking abilities by implementing creative teaching in their lessons.

For a long time, the subject of Home Economics in general education schools was the primary study subject and taught sustainable development principles in daily activities. Development and establishment of technologies in industry and daily life have changed Home Economics's content. This study subject is called Technologies (technologies) in Lithuania, Housekeeping (majturiba) - in Latvia, and it is referred to as Home economics kodundus in Estonia. In many European countries, Home Economics and Technologies, Household Study Subject disappeared altogether. The hours dedicated to study subjects were reduced, such that ancient handicraft forms and ethnographic heritage are no longer considered a priority (Dislere, 2012). However, the study subject, which teaches textile handicrafts and introduces life ecology to school students, has remained in the Baltic states' curricula. Today's 
technological education poses the task of creating conditions for students to get acquainted with the development of technology in the historical context, the relationship of technology with other sciences, to assess technological change in the social environment. Technological education is perceived as a whole of the creative and production process (Primary and Basic Education Framework Programme, 2008). Technological education is implemented by applying the project method of education, enabling a learner to engage in activities following the principles of responsible consumption directly. The content of technologies for students in 5th - 8th forms embraces four areas: nutrition, textile, construction materials, and electronics. The development of responsible consumer culture has been integrated into all the areas mentioned above. This study subject contributes to the development of school students' critical thinking towards mass consumption. The students are taught to choose an ecological way of life and familiarised themselves with the national areas mentioned above. Generally speaking, the study subject teaches them to be 'smart' users of technologies to choose a sustainable lifestyle and preserve it for future generations.

The research presented in the article focuses on the textile part of Technologies subject. This choice was mainly conditioned by the textile handicraft traditions that were historically formed in the Baltic states. For a long time, they were artistic expressions of creativity and expressions of social and economic needs. The nineteenth-century Industrial Revolution changed how textiles were used and attitudes towards the traditional handicrafts, previously handmade, but now produced by machinery. With the development of industrial mass production, the traditional handicraft industry is facing a series of challenges. The popularity of textile handicrafts is low and young people do not want to learn traditional textile techniques. It is often manufactured industrially, and there is no sustainable transmission of traditional textile technologies to future generations. However, handicraft is associated with communities' cultural values and traditions, history, and identities (Donkin, 2001; Wood, 2011). Therefore, it remains essential to the nation's unique cultural heritage (Yang et al., 2018) and is an essential component of traditional Baltic states' traditional culture. If traditional handicraft industries are to be developed sustainably, we need to understand their historical context and experience (Fan and Feng, 2019). Traditional handicrafts carry an abundance of information about traditional cultural codes that embody the unique cultural connotation and value of traditional culture. Also, handcrafted products have an essential role in creative cultural industries (Jakob, 2012; Jakob and Thomas, 2017). Creative industries can transform communities and countries' cultural identity and foster cultural diversity by promoting competitiveness, creativity, design, and innovation (Moalosi et al., 2010). Therefore, the traditional handicraft industry's current development 
requires both external heritage protection of the government and sustainable education, which preserves our culture and allows it to be handed down from one generation to the next. These goals can be achieved by developing a competent and creative teacher.

\section{4. $\quad$ Purpose of the study and research question}

The research aims to investigate the Baltic pre-service Technology teachers' expression of verbal creativity in their final years of study and analyzes the constituent dimension of sustainable textile consumption.

The research problem is formulated as the following question: what dimension of sustainable textile consumption can be identified in the expression of verbal creativity of the students-preservice teachers of technologies in the Baltic states?

\section{Methodology \\ 5.1. The context}

The research is part of a larger project that covered four parts (nutrition; constructive materials; and electronics) of the content of technological education (home economics) within the general curriculum (Primary and Basic Education Framework Programme, 2008) ${ }^{1}$. The participant chose the theme (nutrition, constructive materials, or electronics) of the tasks based on their preferences and was allowed free choice regarding how they performed each task, which identified their inclination towards one or another area of technological education. However, that also affected the number of subjects. All the 76 students participated voluntarily in the study, but only 26 chose the textile-based tasks, which is the focus of this article.

\subsection{Research design}

The qualitative research approach was chosen to evaluate fourth-year students' creativity in the teacher training program of technological education (home economics) of three Baltic states: Lithuania, Latvia, and Estonia. The creative task for this research was designed following recommendations for creativity analysis suggested by Ellis Paulo Torrance (1966, 1974, 1987, 1995), Joy Paulo Guilford (1968), and E. K. H. Kim's (2006) work. Four tasks were given to the students to study their verbal creativity expression and identify the dimension of sustainable textile consumption. The inductive content analysis method was used to process the collected responses (Elo\&Kyngas, 2008). The textual responses of every textile task were divided

\footnotetext{
${ }^{1}$ Primary and Basic Education Framework Programme (2008) is the working program for 2020 technological education in Lithuania.
} 
into categories and subcategories according to the meaning. Subcategories are grouped into categories according to the topic.

The variation-based generalization was used to describe the findings (Patton, 2002, Smaling, 2003). The analysis aimed to explore an undisclosed phenomenon - the use of textile in students' verbal creativity - pre-service teachers of Technologies (Home Economics). Therefore, when summarizing the data, researchers focused on reflecting the phenomenon rather than the theorization. The receptive generalization was applied to our study but not communicative (Smaling, 2003).

\subsection{The instrument}

The Verbal Torrance Test of Creative Thinking (Verbal TTCT) test methodology was used (Torrance, 1966, 1974, 1987, 1995, 2000) to develop the research tasks. The methodological remarks of J. P. Guilford (1968) and K. H. Kim's $(2006,2017)$ were considered by creating the task questions. There were four different tasks with the help of which the participants had to reveal the variety of objects/phenomena; to characterize objects/phenomena; to foresee the possibilities of their use, and foresee the possible consequences of using objects (Fig.1.). To complete the questionnaire's verbal element, participants had to provide an answer in a textual form. The four tasks with varying time limits were about 1) product improvement (List as many examples where wool can be used as possible, $3 \mathrm{~min}$ ); 2) listing possible uses (List as many textile products used 80 years ago as possible, $3 \mathrm{~min}$ ); 3) listing consequences for a specific unlikely situation (Imagine what would happen if the last woman, who can knit, to crochet, to embroider, to sew and weave, died, $3 \mathrm{~min}$ ); 4) unusual/alternative uses (Present as many possible adjectives or any other words that characterize pollutants as possible, $3 \mathrm{~min}$ ). Other activities from the original version of Verbal TTCT were eliminated in the current study. It did not add further meaningful information on an individual's divergent thinking (Kaufman et. al., 2012; Kim, 2017; Said-Metwaly et al., 2020). The completion of the questionnaire of verbal creativity expression in a textual form lasted 12 min. (4 tasks x 3 min.) not including instructions, demographic questions, and short breaks between tasks. 


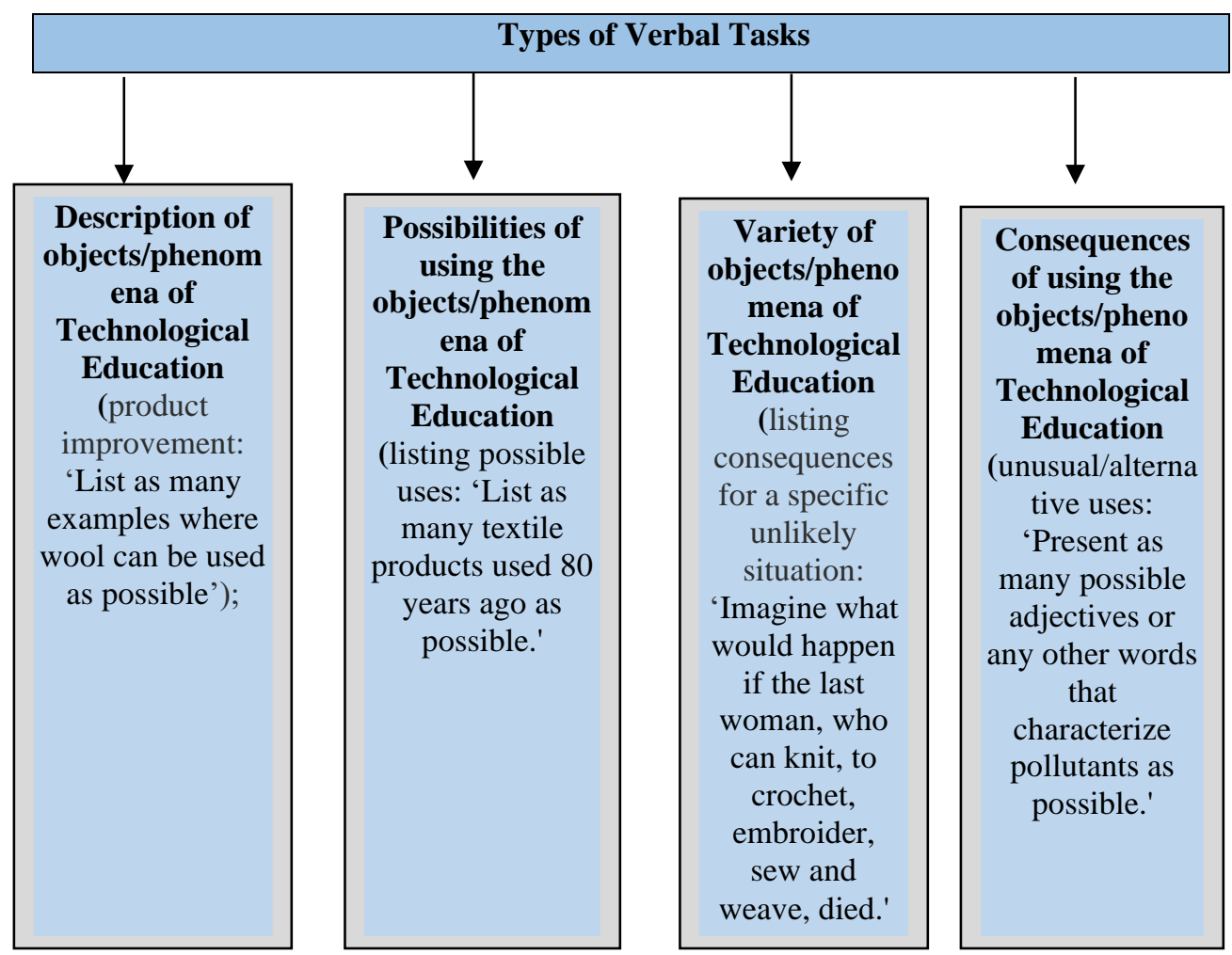

Figure 1. Types of Verbal Tasks in the Study on the Expression of Verbal Creativity (Source: created by authors)

\subsection{Sampling and participants}

The purposive sampling of typical cases (Robinson, 2014, Etikan et al., 2016) was chosen to investigate students - pre-service teachers of Technologies (Home Economics). The sampling criteria were the students studying teacher training studies of Home Economics/Technologies at university. The participants were selected regarding their schools' socioeconomic position, experience, gender, and age to prove a general perspective of verbal creativity. The $1^{\text {nd }}-4^{\text {th }}$ year students from three Baltic States - Estonia, Latvia, and Lithuania universities were chosen for this study. Students studied in full-time and part-time (extramural) studies. Twenty-six university students chose the textile-based tasks from all the seventy-six students that voluntarily participated in the study. The students were age 18 to 51 years old (table 1). The students from Lithuania had the highest average grades for their study achievements $(9,52)$. The study of Technology Education in the Baltic universities was chosen by people of Estonian, Latvian, Lithuanian, and Russian nationalities. The total average of study achievement averages of technologies students in the Baltic States was higher than $80 \%$ (8 points): Lithuanian informants -9.52 , Latvian informants -8.59 , Estonian informants 
- 8.23 (table 1). These higher than average study achievement evaluations indicate the level of knowledge acquired by students during their pedagogical studies and higher than average abilities and accumulated individual experience. High study achievements enable students to apply practical pedagogical activity creatively and flexibly to solve the issues related to educational process organization (Scott, 2007; Hong et al., 2008; Bradley, 2012).

Table 1. Educational and Demographic Characteristics of the Qualitative Research

Participants

\begin{tabular}{|c|c|c|c|c|c|c|c|c|c|}
\hline \multirow[b]{2}{*}{ No } & \multicolumn{3}{|c|}{ Lithuania } & \multicolumn{3}{|c|}{ Latvia } & \multicolumn{3}{|c|}{ Estonia } \\
\hline & Nationality & $\begin{array}{l}\text { The } \\
\text { average } \\
\text { grade } \\
\text { of the } \\
\text { last } \\
\text { term }\end{array}$ & Age & Nationality & $\begin{array}{l}\text { The } \\
\text { average } \\
\text { grade } \\
\text { of the } \\
\text { last } \\
\text { term }\end{array}$ & Age & Nationality & $\begin{array}{l}\text { The } \\
\text { average } \\
\text { grade } \\
\text { of the } \\
\text { last } \\
\text { term }\end{array}$ & Age \\
\hline 1 & Lithuanian & 9,4 & 20 & Latvian & 9,0 & 18 & Estonian & 7,6 & 32 \\
\hline 2 & Lithuanian & 9,0 & 21 & Russian & 6,8 & 19 & Estonian & 9,0 & 27 \\
\hline 3 & Lithuanian & 9,7 & 21 & Latvian & 9,0 & 21 & Estonian & 8,2 & 29 \\
\hline 4 & Lithuanian & 10,0 & 21 & Latvian & 9,7 & 22 & Estonian & 8,7 & 50 \\
\hline 5 & Russian & 9,03 & 21 & Latvian & 8,6 & 21 & Estonian & 8,3 & 46 \\
\hline 6 & Lithuanian & 10,0 & 21 & Latvian & 8,3 & 23 & Estonian & 8,4 & 51 \\
\hline 7 & & & & Russian & 9,8 & 21 & Estonian & 7,6 & 29 \\
\hline 8 & & & & Latvian & 9,0 & 21 & Estonian & 8,0 & 41 \\
\hline 9 & & & & Latvian & 9,0 & 22 & & & \\
\hline 10 & & & & Latvian & 8,0 & 19 & & & \\
\hline 11 & & & & Latvian & 8,0 & 20 & & & \\
\hline 12 & & & & Latvian & 7,9 & 19 & & & \\
\hline
\end{tabular}

\subsection{Limitation}

There are some limitations to the study. The number of observations used in the empirical study is relatively small due to choosing a rather homogenous sample. The small number of the students was conditioned by the small number of Technologies/Home economics students. Therefore, the findings should be treated as indicative evidence instead of unequivocal truth. The test was carried out once for all the students of the program. It would be recommended to repeat the study at least three years to get more accurate results. The first verbal creativity expression features - fluency, flexibility, originality- were not analyzed in this article.

\section{Results of research}

Textiles are just one component in technological education (Home economics), and their importance in the context of consumer culture is wellestablished. The dimension of expression of consumption culture among students of technologies is characterized through four themes found during the 
content analysis: "Examples of wool use," "Consequences of extinction of handicraft production," "Range of textiles used 80 years ago," and "Characterisation of pollutants." They are also expressed in eighteen qualitative categories, which embrace forty-two subcategories.

\section{The first theme - "Examples of wool use."}

The content of the first textile-related task on identifying verbal creativity was linked to the variety of ways to use textile: list as many examples where wool can be used as possible. The answers of the first creative tasks were divided into five categories according to their meaning: material for practical activities; clothes; handicraft items; wool as a raw material; wool extraction and its qualities.

The category of material for practical activities falls into three subcategories: knitting, sewing, and felting. The students distinguished three main activities where wool can be used. The students from Lithuania and Latvia use wool "for knitting sweaters and other clothes" and sewing coats and carpets. The following difference was observed: Lithuanian students noted that it was possible to use wool to sew clothes. The students from Latvia state that wool can be used for textile products used at home. The students from Latvia do not refer to wool felting as a process. The Estonians do not connect the use of wool with the process and only list products.

The category Clothes is divided into two subcategories: warm clothes and limb textiles. The students from Lithuania mentioned only sweaters and scarfs. The Estonian students provided a relatively wide range of clothes, and the Latvian students gave an abstract explanation: "various clothes can be made of wool." The responses from Lithuania and Estonian students were attributed to the subcategory of limb textiles.

The category Handmade products comprise two subcategories: items for decoration; and textile products used in daily life. The subcategory of items for decorations contains responses from all the Baltic states. However, the widest variety of responses was observed among the Estonian students: "for building a snowman," "illustrations that imitate domestic animals," " you can make clouds, snow," "for cotton buds," and others. The students from Latvia mentioned wool dyeing. The subcategory of textile products used in daily life contains such answers of Estonian students as bed textile, "cushions," and "baby swaddles." It was pointed out that wool swaddles can be used ecologically as diapers. This answer allows concluding that the students possess knowledge of baby hygiene and responsible consumption. The students from Latvia referred to bed linen and carpets. The Lithuanian students mentioned bed linen, textile products used in the kitchen, and a car. That is one of the broadest ranges of using wool. 
The category Wool as a raw material consists of five subcategories: for production of threads; for production of fabrics; stuffing; as a construction material; and as an assistive product. All the Baltic states' responses were found only in the subcategory of threads production, but no significant differences were observed there. The responses in the subcategory of production of fabrics were only from the Lithuanian students. The students from Lithuania use wool for bed textile in the subcategory of stuffing. In contrast, the Estonian students expanded the range of wool use with "for finishing a handicraft item," "stuffing the toy" in this subcategory. The subcategories of construction material and assistive products contained the responses of students from Latvia and Estonia. The Latvian students used wool "for finishing a place for living" for insulation, whereas the Estonian students wanted to use wool to make a hamster house.

The category of Wool extraction and its qualities consist of two subcategories: extraction and qualities. The students from Lithuania stated that wool could be extracted from sheep. The Latvian students pointed out that "wool is extracted from various animals," but they mentioned only sheep and dogs. They also demonstrated their knowledge, stating that "wool can be natural and synthetic." The students from Estonia did not consider the extraction of wool and wool qualities. The wool qualities were indicated only by the students from Latvia: "it is very warm."

Generalizing it can be stated that students from Latvia's responses are focused on the improvement of household, whereas the Lithuanian students targeted at occupations, decoration. The Estonian responses were directed to decorative details and objects. It should be noted that the most significant amount of knowledge of consumer culture was found in the responses of Estonian students.

The second theme - "Consequences of extinction of handicraft production." The second textile-related task on the identification of verbal creativity was linked to a utopian situation. The analysis of the qualitative research allowed dividing the responses of the creative task into six categories: limitation of needs; alternatives of information sources; change of leadership in handicrafts; social and economic changes; advantages of handicrafts; absence of consequences.

The category of Limitation of needs consists of two subcategories: reduction of range of textiles; and alternative handicrafts. The responses of students from the Baltic states were closely related to warm woolen stocking. The students from Latvia and Lithuania referred to warm woolen stockings in the context of Christmas and communication in the family. One can easily envisage the retention of a present's primary purpose - to surprise, to delight, to establish the link between the presenter and the receiver of the gift. If Christmas is related to practical handmade presents, it can be regarded as a 
fact of value expression for communication, the establishment of close relations, and quality time together. It is the opposite of the prevailing consumerism and promising approach to preserving sustainable traditions.

The Latvian students connect homemade works with the exceptionality of nation and identity and emphasize the importance of learning this identity. The students from Latvia think that handicrafts create conditions for exceptionality, convenience, and family closeness: "all the things would be similar"; "we would not have woolen stockings, which would make our feet warm in the winter evenings." Estonia students see handicrafts as a possible exception: "unique jewelry and authentic folk handicrafts would disappear." There is a positive attitude towards time-related change: "in the planet of these days, there would not be yarn and sweaters," "they would not have warm stockings." However, the connection between handicrafts and ethnicity, necessity, and values was not identified, and neither were essential changes and negative consequences envisaged. The family, as a value, was referred to in the responses of Latvian and Lithuanian students. The students from Lithuania identified handicrafts with various clothing, an element of personality formation in the educational process, an integral part of national identity, a means of revelation of individuality. The students from Latvia prioritized handmade clothes over mass-produced clothes. There was an insight about the value-based relation to the creator and respect for invested efforts.

The category Alternatives of information sources consists of two subcategories: practical learning of handicrafts and sources of learning. Even if it is non-formal daily unconscious education, the students from the Baltic states see the educator as the primary source. In the discussed case, it is a woman who can knit, embroider, weave, and sew by hand. The following sources are possible: books, museums; the Internet; television; video material; and men. The students from Latvian students stated that if people are deprived of opportunities to experience hand work directly participating in the creation, museums could be an alternative. The Latvian students also see museums as alternative sources of information. They say that nobody can replace a unique person who has mastered handicrafts.

Meanwhile, Estonia students see another person as a replacement for a woman who has mastered handicrafts. Moreover, they present alternative sources of information: "handicrafts books would remain, teaching material and others. The handwork skills of women should be recorded, and later this material can be demonstrated in schools, on television or the internet". An educator is not the only and irreplaceable source of knowledge. The underestimation of abilities to make handicrafts is grounded by the presented answer, "dragons can take on handicrafts." The content analysis of responses allows assuming about students' different experience choosing, analyzing, 
suggesting, or choosing alternative information sources. In non-typical situations, only the Estonian students envisaged a variety of sources. The responses of Estonian students contained certain freedom and even jokes. Meanwhile, the Lithuanian and Latvian students see a person as an irreplaceable source of information and want them to be professionals.

The students listed alternative sources of information, including museums, which were most frequently mentioned in Latvian students' responses. The data analysis allows stating that the Latvian students perceive museums as sources of information and as a place where it is possible to spend time. They regard museums as an essential element of the national identity and a prerequisite for understanding the present. Such an attitude was not observed in the responses of Estonian and Lithuanian students. According to the official statistical data on the number of museums in the Baltic states, Estonia has 244 museums, which the most significant indicator among the Baltic states (Statistics Estonia, 2019). Latvia has much fewer, i.e., 151 museums (Statistics Latvia, 2019), and in Lithuania, the number of museums is the smallest and is equal to 104 (Statistics Lithuania, 2019).

The category Change of leadership in handicrafts is divided into the subcategories of occupation and men's handicrafts. The woman's picture is somewhat archaic in students' responses from Latvia and Lithuania: the woman as a family breadwinner, cloth maker, comforter, and protector of the family hearth. The stereotypical division of labor according to gender. Only in emergencies can men take over female duties: "to prevent this from happening, men could perform these duties." The woman can be identified as a person, who takes care of all the well-being of the household, and she can rarely get help: "people $\langle\ldots>$ create new technologies, which would work instead of women". The Estonian students again make jokes that "it would be interesting when men with beer bellies would teach children." However, a stereotypical attitude towards children's teaching can be envisaged. This is perceived as if the duty of women. Men's participation in the process of education is presented as a funny situation.

The category Social and economic changes embrace three subcategories: international relations, internal economic relations of the country, internal social relations of the country. The students from Lithuania and Latvia link their garments and the household environment with handicrafts made by women. The Lithuanian students connect the fact described above to establish relationships with neighboring countries in the handicraft trade. The emphasis on handicrafts' value was emphasized: "we would buy all the products for a high price from foreign countries." The Latvian students also stressed the social aspect: "men would search for a woman of other nationalities, who would know how to do all these things," "men would marry girls from neighbouring countries to be provided with handmade clothes." The 
reasons for rational wedding, which were preconditioned by the changing social environment, were indicated. The Estonian students presented the importance of exchanging ideas for creation and economy: "we can use handicrafts of second hands." Therefore, the picture of a woman as a creator of the family's well-being was identified again.

The category Advantages of handicrafts consists of only one subcategory - positive qualities (Table 2), where an essential argument is as follows "self-made clothes are always warmer." The category Absence of consequences also has only one subcategory - the absence of neighboring. The students stated that "nothing would happen," or perhaps "many would not even notice, special plants and factories would remain." If a person is not a buyer of handmade products, to think of possible consequences of the presented strange situation can be complicated. If I am not a user of handicrafts Today, I will not be one tomorrow. A lack of global attitude was envisaged.

In the expression of verbal creativity, an evident influence formed in the environment of unique national culture can be seen in the individual's thinking. By changing the cultural environment, we also influence personal creative expression, one of the strongest arguments to introduce changes in a flexible, sensitive, careful, and responsible way. The creative expression of a person is found in various areas of activity; therefore, changes will manifest in an individual's activity.

The third theme - "Range of textiles used 80 years ago". The third task's content, the textile-related task on identifying verbal creativity, is related to various historical textile products. After analyzing qualitative research data, the third creative task's responses were divided into two categories: textiles used in the household; people's clothes.

The category Textiles used in households consists of four subcategories: bed linen, window textile; table linen; floor and wall textile. The category of People's clothes embraces four subcategories: basic garment; headgear; limb textiles; another garment. In the subcategories of main garment and headgear, both men's and women's clothes were found. It should be noted that only the students from Lithuania provided answers to this question, and their range of answers was relatively narrow. We can see that the student's knowledge of history in textile is limited.

The fourth theme - "Characterisation of pollutants." The content of the fourth textile-related task on identifying verbal creativity is related to the characterization of objects. The qualitative research data analysis allowed dividing the responses into five categories: diagnostics according to five human senses; psychological evaluation; current impact; qualities of pollutants; possible solutions and consequences.

The category Diagnostics according to five human senses, is divided into three subcategories: visual diagnostics, smell diagnostics, auditory 
diagnostics. The students from Estonia used three out of five human senses to characterize pollutants. Sight and smell were used by the students from Latvia, whereas the Lithuanian students employed only smell. The receptors of touch and taste were not used at all for the characterization of pollutants. The category Psychological evaluation consists only of one subcategory personalized. The students from Latvia and Estonia provided pollutants with human qualities: "smart," "dreadful," and others. Such an attitude can be interpreted as considering pollutants to be an integral own existence and existence of the world. The category Current impact is divided into two subcategories: impact on a person; impact on the environment. The responses in this category were neither abundant nor varied. No significant differences were identified in them either. The category Qualities of pollutants splits into two subcategories: variety and physical qualities. In the subcategory of variety, Lithuania students pointed out that pollutants are "prevalent these days" and "widely used." The Latvian students emphasized the extent of pollutant spread. The Estonian students pointed out the ecological aspect: "recycled," "cleaned," and others. The category Possible solutions and consequences consist of two subcategories - solution options; possible consequences. The first subcategory contained only responses from Estonia, whereas in the second - only from Lithuania. Estonia students pointed out three possible solutions to reduce pollutants: scientific path conducting research; everybody's duties to collect garbage; technological solutions related to using filters. The Lithuanian students envisaged possibilities for the appearance of "mutants." They as if jokingly added that "creatively used pollutants can create life."

\section{Discussion}

The analysis of research data reveals local thinking of students and the consideration of their own needs. The tasks' choices are not refined or based on beliefs, values, or support of own country. Insufficient critical thinking is identified. According to A. Pawłowski (2007), the lack of critical thinking leads to a faulty double interpretation of sustainable development ideas when considerable attention is paid to further goals of society's activity and currently occurring problems are ignored. The lack of critical thinking creates conditions for the development of a consumer society without global thinking skills. Therefore, education based on critical thinking and sustainability principles is a key factor in preserving textile traditions.

In most cases, the educational process's success is predetermined by the educator's competencies (Čirčin, 2016; Wilhelm et al., 2019). The Baltic state's students see the person - the educator as the primary source of such kind of information, and they express a wish for this person to be a professional. This is particularly important for the students from Lithuania and Latvia. The 
students from Estonia do not think that the educator is the only and indispensable source of knowledge. The focus of students from Estonia on the action or function rather than on the person. Students' responses from all the countries revealed a stereotype about an educator working with children: it has to be a woman. Such an attitude can be predetermined by the Baltic states' situation, whereas the majority of teachers are women.

On the one hand reflects the situation when men are underrepresented in caregiving fields, such as nursing and teaching (Croft, Schmader, \& Block, 2015). On the other hand, it demonstrates that women's role in the transmission of traditions is vital; hence, we do not forget to take advantage of current opportunities while seeking to achieve gender equality in education.

This research shows that tasks on the expression of verbal creativity reveal the various dimensions of sustainable textile consumption. In the theme of 'Examples of wool,' the students distinguished three main activities where wool can be used: knitting, sewing, and felting. They also mentioned two types of clothes: warm clothes and limb textiles. The category 'Wool as raw material' students named mainly five types of production: threads, fabrics, stuffing, construction material, and assistive products. The analysis of the textile-related task 'Consequences of extinction of handicraft production' allowed dividing the responses into six categories: limitation of needs; alternatives of information sources; change of leadership in handicrafts; social and economic changes; advantages of handicrafts; absence of consequences. The task's results Range of textiles used 80 years ago gave us two categories: Textiles used in household and People's clothes. Students named four types of textiles used in households: bed linen, window textile; table linen; floor and wall textile. People's clothes embrace four subcategories from students' answers: basic garment; headgear; limb textiles; additional garment. When students were asked to present as many possible adjectives or any other words that characterize pollutants as possible, the answers revealed five categories: diagnostics according to five human senses; psychological evaluation; current impact; qualities of pollutants; possible solutions and consequences. The students' responses indicated good knowledge of environmental pollution, existing, alleged, and possible consequences and ways of their reduction.

It has been noticed that the idea of creativity identification/educational tasks can be treated as a form of an educational method for the development of sustainable textile consumption. The content for the formulation of tasks is presented following sustainable development or the themes of sustainable textile consumption. The research enabled the design of an integral model of tasks on identification/development of verbal creativity expression and identification/development of sustainable textile consumption (Fig. 2). 


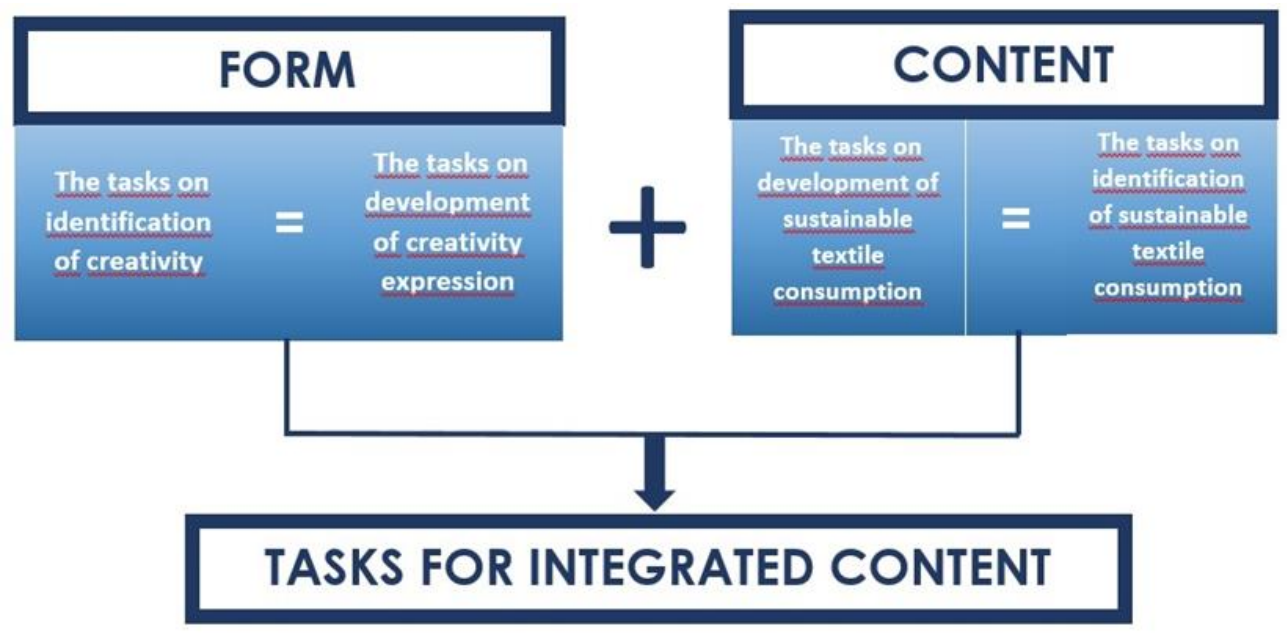

Figure 2. The integral model of tasks on identification/development of verbal creativity expression and identification/development of sustainable textile consumption

(Source: created by authors)

Creativity emerges only as a result of cognitive, affective, and dynamic cultural activity. This can only be possible with creative training. The tasks used to identify verbal creativity can be regarded as form, whereas consumer culture and technological education (home economics) can be regarded as content. This principle is used to create tasks on the development and identification of creativity and consumer culture. In other words, analysis, investigation, communication, and learning in daily life contribute to the development of creativity which ultimately creates a more conscious consumer.

\section{Conclusion}

The research revealed that future technology teachers in the Baltic States could creatively communicate the possibilities of using wool in textiles and describe the possible consequences of the disappearance of textile crafts quite broadly. The disappearance of textile handicrafts is associated with them by the decline in the range of textile products and the leisure activities and traditions of the people. Informants attribute the possible disappearance of textile handicrafts to social and economic changes. Students have extensively described textile pollutants, distinguishing the unacceptable features of contaminated textiles and describing the effects on humans and their environment, the diversity of pollutants, the effects, and ways to overcome them. However, when describing textile pollutants, Lithuanian and Latvian informants were the least creative. The Lithuanian and Latvian students demonstrate the understanding of the handicraft processes but the Estonian students list more final products. 
The students' responses indicated good knowledge of environmental pollution, existing, alleged, and possible consequences and ways of their reduction. Also, the present research disclosed students understanding that handicrafts are not related to ethnicity, values, or a phenomenon, which calls for exceptional protection. Therefore, the development of students' creativity - future Home economics/Technology teachers can play an essential role in implementing curriculum towards sustainable textile consumption.

\section{References:}

1. Beaty, R. E., Chrisense, A. P., Bendek, M., Silvia, P. J., \& Schacter D. L. (2017). Creative constraints: Brain activity and network dynamics underlying semantic interference during idea production, NeuroImage, 148: 189-196. doi: 10.1016/j.neuroimage.2017.01.012

2. Bloom, B. S. Ed. (1956). Taxonomy of educational objectives: The classification of educational goals. Handbook 1: Cognitive domain. New York: David McKay.

3. Bradley, F. (2012). Creativity: does place matter?, London Review of Education, 10(2): 145-157. DOI: 10.1080/14748460.2012.691280

4. Čirčin, N. (2016). Overview of Didactic Methodical Organization of University Teaching by Bologna Concept of Higher education, Interdisciplinary Description of Complex Systems, 14(1): 52-60. Doi: 10.7906/indecs.14.1.5

5. Croft, A., Schmader, T., \& Block, K. (2015). An underexamined inequality cultural and psychological barriers to men's engagement with communal roles, Personality and Social Psychology Review, 19(4): 343-370. doi: 10.1177/1088868314564789

6. Dislere, V. (2012). Methodology structure for training teachers of Home economics and Technologies, Rural environment. Education. Personality. Proceedings of International Scientific Conference, 5, 201-208. https://llufb.llu.lv/conference/REEP/2015/Latvia-UnivAgricult-REEP-2015proceedings.pdf

7. Donkin, L. (2001). Crafts and Conservation: Synthesis report for ICCROM. Available at: https://www.iccrom.org/sites/default/files/201712/iccrom_02_craftsandconservation_en.pdf (accessed on 10 of March 2021)

8. Elo, S.; Kyngas, A. (2008). The qualitative content analysis process. $J$. Adv. Nurs., 62, 107-115.

9. Etikan, I., Musa, S.M., Alkassim, R.S. (2016). Comparison of Convenience Sampling and Purposive Sampling, American Journal of Theoretical and Applied Statistics, 5(1): 1-4. 
http://article.sciencepublishinggroup.com/html/10.11648.j.ajtas.2016 0501.11.html

10. Fan, K.-K., Feng, T.-T. (2019). Discussion on Sustainable Development Strategies of the Traditional Handicraft Industry Based on Su-Style Furniture in the Ming Dynasty, Sustainability: 11(7). doi: 10.3390/su11072008

11. Guilford, J. P. (1950). Creativity. American Psychologist, 5: 444-454. doi: $10.1037 / \mathrm{h} 0063487$

12. Guilford, J. P. (1968). Creativity, intelligence, and their educational implications. San Diego, CA: EDITS/ Robert Knapp.

13. Hong, J. C., Horn, J. S., Lin C. L., \& Lin, Ch. (2008). Competency disparity between pre-service teacher education and in-service teaching requirements in Taiwan. International Journal of Educational Development, 28 (1): 4-20. doi: 10.1016/j.ijedudev.2006.12.004

14. Jakob, D. (2012). Crafting your way out of the recession? New craft entrepreneurs and the global economic downturn, Cambridge Journal of Regions, Economy and Society, 6(1): 127-140. doi: $10.1093 /$ cjres/rss022

15. Jakob, D., Thomas, N.J. (2017). Firing up craft capital: the renaissance of craft and craft policy in the United Kingdom, International Journal of Cultural Policy, 23(4): 495-511 doi: 10.1080/10286632.2015.1068765

16. Kaufman, J.C., Plucker, J.A., Russell C.M. (2012). Identifying and assessing creativity as a component of giftedness. Journal of Psychoeducational Assessment, 30(1): 60-

73. DOI: $10.1177 / 0734282911428196$

17. Kim K.H. (2017). The Torrance Tests of Creative Thinking - Figural or Verbal: Which one should we use? Creativity Theories - Research - Applications, 4, 302-321, 10.1515/ctra-2017-0015

18. Kim K.H., Cramond, B. Bandalos D.L. (2006). The latent structure and measurement invariance of scores on the Torrance Tests of Creative Thinking - Figural Figural. Educational and Psychological Measurement, 66, 459-477, 10.1177/0013164405282456

19. Kim, K. H. (2006). Is Creativity Unidimensional or Multidimensional? Analyses of the Torrance Tests of Creative Thinking. Creativity Research Journal, 18 (3): 251-259. doi: 10.1207/s15326934crj1803_2

20. Krathwohl, D. R. (2002). A revision of Bloom's taxonomy: An overview. Theory into Practice 41 (4): 212.

21. Leclerc, R. (2017). Play, Think, Design: Play as a Means to Acquire and Enhance Design Thinking Skills. In Design Education for 
Fostering Creativity and Innovation in China (pp. 179-211). IGI Global. DOI: 10.4018/978-1-5225-0911-0.ch008

22. Moalosi, R., Popovic, V., \& Hickling-Hudson, A. (2010). Cultureorientated product design, International Journal of Technology and Design Education, 20(2): 175-190. doi: 10.1007/s10798-008-9069-1

23. Patton, M. Q. (2002). Qualitative research \& evaluation methods. Thousand Oaks (Calif.) [etc.], Sage Publications.

24. Paulus P.B., Brown V.R. (2007). Toward more creative and innovative group idea generation: a cognitive-social-motivational perspective of brainstorming. Social and Personality Psychology Compass 1(1): 248265.

25. Pawłowski, A. (2007). Barriers in Introducing Sustainable Development - Ecophilosophical Point of View, Problemy Ekorozwoju/ Problems of Sustainable Development, 2(1): 59-65. https://ekorozwoj.pollub.pl/index.php/number-212007/barriers-inintroducing-sustainable-development/. ( accessed on 10 May of 2021).

26. Primary and Basic Education Framework Programme (Technologies) (2008). LR Ministry of Education, Vilnius. $<\mathrm{http} / /$ portalas.emokykla.lt/bup/Documents/Pradinis\%20ir\%20pagri ndinis\%20ugdymas/Technologijos.pdf $>$. ( accessed on 10 May of 2021).

27. Puryear, J. S., Kettler, T., \& Rinn, A. N. (2017). Relationships of personality to differential conceptions of creativity: a systematic review. Psychology of Aesthetics, Creativity, and the Arts, 11(1): 5968. doi:10.1037/aca0000079

28. Robinson, O. C. (2014). Sampling in Interview-Based Qualitative Research: A Theoretical and Practical Guide. Qualitative Research in Psychology, 11 (1): 25-41. doi: 10.1080/14780887.2013.801543

29. Said-Metwaly S., Kyndt E., Van den Noodtgate W.(2020) The factor structure of the Verbal Torrance Test of Creative Thinking in an Arabic context: Classical test theory and multidimensional item response theory analyses. Thinking skills and creativity. 35. 1871-1871. https://doi.org/10.1016/j.tsc.2019.100609

30. Said-Metwaly S., Fernández-Castilla B., Kyndt, W E., Van den Noortgate. (2018). The factor structure of the Figural Torrance Tests of Creative Thinking: A meta-confirmatory factor analysis. Creativity Research Journal, 30 pp. 352-360, 10.1080/10400419.2018.1530534

31. Scott, G. A. (2007). Teacher Quality: Approaches, Implementation, and Evaluation of Key Federal Efforts: GAO-07-861T. GAO Reports, 5 (17): 1-17. https://www.gao.gov/assets/120/116677.pdf 
32. Smaling, A. (2003) Inductive, analogical, and communicative generalization. International Institute for Qualitative Methodology (IIQM), 2 (1): 52-67.

33. Statistics Estonia: Statistical database / Museums by Indicator and Year

https://andmed.stat.ee/en/stat/sotsiaalelu__kultuur_muuseumid/KU0 5/table/tableViewLayout1 (accessed on 10 of March 2021).

34. Statistics Latvia: Official statistics portal / Activities of museums (2019): https://stat.gov.lv/en/metadata/8238-activitiesmuseums/sims2 (accessed on 10 of March 2021).

35. Statistics Lithuania: Ministry of Culture of the Republic of Lithuania / Museums and Galleries (2019): https://lrkm.lrv.lt/en/activities/museums-and-galleries (accessed on 10 of March 2021).

36. Sun, M., Wang, M. Wegerif, R. (2019). Using computer-based cognitive mapping to improve students' divergent thinking for creativity development. British Journal of Educational Technology 50: 2217-2233.

37. Torrance E.P. (2000). Preschool creativity. B.A. Bracken (Ed.), Psychoeducational assessment of preschool children (3rd ed.), Allyn and Bacon, Needham Heights, MA pp. 349363.

38. Torrance, E. P. (1966). The Torrance Tests of Creative Thinking: Norms-technical manual Personal Press, Lexington, MA.

39. Torrance, E. P. (1974) Norms-technical manual, Torrance tests of creative thinking. Bensenville, IL: Scholastic Testing service.

40. Torrance, E. P. (1987). The nature of creativity as manifest in its testing. The blazing drive: The creative personality. Buffalo, N. Y, 4376.

41. Torrance, E. P. (1995). Why fly? Norwood, NJ: Ablex.

42. Towards a sustainable Europe by 2030, https://ec.europa.eu/commission/sites/betapolitical/files/rp_sustainable_europe_30-01_en_web.pdf (accessed on 10 of March 2021).

43. Villanova A.L.I., Pina E Cunha M. (2020). Everyday Creativity: A Systematic Literature Review. Journal of Creative behaviour. 0 (0), 1-23. https://doi.org/10.1002/jocb.481

44. Wilhelm, S., Forster, R., \& Zimmerman, A.B. (2019). Implementing Competence Orientation: Towards Constructively Aligned Education for Sustainable Development in University-Level Teaching-AndLearning, Sustainability: 11(7). doi: 10.3390/su11071891 
45. Wood, S. (2011). Sustaining crafts and livelihoods: handmade in India, Craft + Design Inquiry, 3: 1-15. Doi:10.22459/CDE.03.2011.07

46. Yang, Y., Shafi, M., Song, X., \& Yang R. (2018). Preservation of cultural heritage embodied in traditional crafts in the developing countries. A case study of Pakistani handicraft industry. Sustainability, 10: 1336. doi:10.3390/su10051336

47. Yerevan Communique (2015). Bologna Process, http://www.smm.lt/uploads/documents/Papildomas\%20meniu2/Bolo nijos_procesas/Communique.pdf. (accessed on 24 of October 2019).

48. Zmigrod, S. (2014). The role of the parietal cortex in multisensory and response integration: Evidence from transcranial direct current stimulation (tDCS). Multisensory Research, 27(2): 161-172. DOI: 10.1163/22134808-00002449 